\title{
Truth, respect and recognition: addressing barriers to Indigenous maternity care
}

\author{
Janet Smylie MD MPH, Wanda Phillips-Beck RN MSc
}

— Cite as: CMAJ 2019 February 25;191:E207-8. doi: 10.1503/cmaj.190183

See related article at www.cmaj.ca/lookup/doi/10.1503/cmaj.181002

$\mathbf{F}$ or those of us living and working in First Nations, Inuit and Métis communities, the finding of the linked research by Wall-Wieler and colleagues, ${ }^{1}$ that mothers with a history of child apprehension are less likely to receive adequate prenatal care in subsequent pregnancies, comes as no surprise.

To get to solutions, we must first honestly describe the problem. Most children in care in Manitoba are First Nations; why this is so and why their parents may be reluctant to access health services, go far beyond what is considered in the linked research. ${ }^{1} \mathrm{~A}$ strong argument can be made that there is historic continuity between the original "civilizing mission" of European colonizers, used to justify the abduction of Indigenous children from their families, and current overrepresentation of First Nations, Inuit and Métis in the child welfare system. ${ }^{2}$ Indigenous peoples have been stereotyped as "bad parents" since Europeans first arrived in the Americas. Bad parents emerged as one of the top 10 stereotypes of Indigenous peoples held by health and social service providers in a recent presentation of research. ${ }^{3}$ Accumulating evidence indicates that such negative stereotyping is linked to differential treatment ${ }^{4}$ and that Indigenous patients commonly experience racism when trying to access health and social services. ${ }^{5}$

The core "exposure" of having a child placed in care needs, therefore, to be understood as part of a complex causal pathway in which implicit and explicit anti-Indigenous racism and linked gaps in cultural safety competencies interfere in provider-patient relationships and clinical decision-making. Wall-Wieler and colleagues' findings, in this context, beg for an Indigenous-specific analysis to understand better what is driving inadequate prenatal care.

As Indigenous care providers, we regularly witness clinical incidents involving inappropriate judgments of and inhumane actions toward Indigenous parents. Some narratives, such as, "these people tend to have too many children and can't take proper care of them," are passed from preceptor to student during medical training.

In 1997, as a newly minted family doctor providing obstetrical care, the lead author started a weekly Indigenous-focused maternity clinic in the walk-in area of a downtown Ottawa community health centre to address barriers facing First Nations,

\section{KEY POINTS}

- Colonial policies and anti-Indigenous racism are important determinants of health service access; this should be considered in any analysis of use of prenatal care for Indigenous mothers.

- There is a resurgence of Indigenous community-led models of maternity care and evidence supporting their effectiveness across multiple outcomes.

- Absence of Indigenous representation and community engagement in a research study where it is known that the exposed cohort is largely First Nations is not acceptable in this era of Truth and Reconciliation.

Inuit and Métis women in accessing prenatal care. These barriers included but went beyond the basic material needs such as transportation and the need to prioritize housing, food security and safe child care over scheduled medical appointments. Women feared being misunderstood and incorrectly judged by culturally biased maternity care providers who, without reflection on how social stereotyping was driving their clinical interactions and decision-making, would deem them inadequate mothers-to-be and contact child protection agencies. She quickly became known as the Métis doctor who provided nonjudgmental and supportive maternity care. She promised that if a call to a child protection agency needed to be made, rather than working "behind their back," this would be done together.

This clinic formed a small piece in a decades-long international movement aimed at (re)asserting Indigenous rights and sovereignty in the domain of Indigenous mothering and maternity care. There has been much change in the last 2 decades in the domains of both Indigenous maternity care and understanding and addressing race preference bias among health care providers. The history and negative effects of the colonial dismantling of traditional systems of maternity care and parenting among First Nations, Inuit and Métis through legislation and policies, including the suppression of traditional midwifery practice, residential schools and the Sixties Scoop, are increasingly documented and acknowledged. ${ }^{2,6}$ These processes are also acknowledged to be ongoing, contributing to a situation where there are now more 
Indigenous children in Canada's child welfare system than when residential schools were at their peak. ${ }^{2,7}$

Resurgence of and support for Indigenous community-led models of care, including Indigenous midwifery and doulas across Canada $^{8}$ and internationally, ${ }^{9}$ is exciting. Accumulating evidence shows how First Nations, Inuit and Métis community leadership of prenatal, reproductive, and child health services and programming for First Nations, Inuit and Métis peoples is linked to success across many outcomes. ${ }^{10}$ The Stronger Families Program, developed by regional Indigenous health service providers and an Indigenous health research unit in Brisbane, Australia, in response to the overrepresentation of Indigenous children in child protection agencies, reduced child apprehensions to 0 in a 14-month period, by providing interdisciplinary, comprehensive, and culturally safe clinical and social supports, and defining referral pathways. ${ }^{9}$ Similar initiatives are underway in Canada. In Manitoba First Nations, the Strengthening Families Maternal Child Health Program, Indigenous Doula Initiative and Cree Birth Initiatives each centrally position traditional knowledge and practice and apply strength-based philosophies to their health-promotion strategies that operate across individual, family and community levels.

Imagine for a moment health services for First Nations, Inuit and Métis peoples across Canada that actively facilitate positive social change. Imagine health services led by First Nations, Inuit and Métis that are actualizing care founded on self-determined First Nations, Inuit and Métis concepts of health and well-being, concepts such as "āniskētastāwin," a Cree term that grandmother Madeleine Kétéskwēw Dion Stout interprets as "attachment through the ages where all people and things are connected."

As former National Grand Chief Phil Fontaine said at an Indigenous health conference addressing Indigenous genocide in Canada, "The answers lie in our communities ...". ${ }^{11}$ Unfortunately, the wisdom in this statement is still commonly overlooked in the health sciences and by researchers. Given current ethics guideline requirements for Indigenous community engagement, ${ }^{12}$ we were surprised to see, for example, that the linked research study ${ }^{1}$ was undertaken without any explicit input from Indigenous peoples or organizations. That the "exposed" cohort in the linked study was very likely to be largely Indigenous is not mentioned until the end of the article's interpretation, although the overrepresentation of First Nations children in the Manitoba child welfare system is common knowledge. ${ }^{7,13}$ The conspicuous absence of Indigenous representation in the construction of the research perpetuates systemic disregard for Indigenous peoples and knowledge in research. In this era of Truth and Reconciliation, the call for Indigenous leadership of Indigenous affairs is clear - both in services to support our families when they need assistance and in the conduct of research that is about us. ${ }^{2}$

We encourage researchers and physicians to reflect often on how individual and social reluctances to acknowledge and address hard truths, such as the persistence of colonial policies and anti-Indigenous racism, interferes with strong science and positive social change.

\section{References}

1. Wall-Wieler E, Kenny K, Lee J, et al. Prenatal care among mothers involved with child protection services in Manitoba: a retrospective cohort study. CMAJ 2019;191:E209-15.

2. Honouring the truth, reconciling for the future: summary of the final report of the Truth and Reconciliation Commission of Canada. Winnipeg: The Truth and Reconciliation Commission of Canada; 2015.

3. Cowan YR, Harding L. Responding to anti-Indigenous racism in the health care system. West Vancouver (BC): First Nations Health Authority; 2017 Oct. 4. Available: www.fnha.ca/eventsContent/Documents/FNHA-BCPSQC-Responding-to-Anti -Indigenous-Racism-in-the-Health-Care-System-Slides.pdf (accessed 2019 Feb. 11).

4. Chapman EN, Kaatz A, Carnes M. Physicians and implicit bias: how doctors may unwittingly perpetuate health care disparities. J Gen Intern Med 2013;28:1504-10.

5. Allan B, Smylie J. First Peoples, second class treatment: the role of racism in the health and well-being of Indigenous peoples in Canada [executive summary]. Toronto: Wellesley Institute; 2015.

6. Jasen P. Race, culture, and the colonization of childbirth in northern Canada. Soc Hist Med 1997;10:383-400.

7. Turner A. Insights on Canadian society: living arrangements of Aboriginal children aged 14 and under. Cat no 75-006-X. Ottawa: Statistics Canada; 2016 Apr. 13. Available: www150.statcan.gc.ca/n1/pub/75-006-x/2016001/article/14547-eng. pdf (accessed 2019 Feb. 11).

8. Aboriginal midwifery practices in Canada. Montréal: National Aboriginal Council of Midwives; 2012. Available: http://aboriginalmidwives.ca/aboriginal-midwifery /practices-in-Canada (accessed 2019 Feb. 11).

9. Institute for Urban Indigenous Health. Stronger Families Research Report. Brisbane (Australia): Institute for Urban Indigenous Health; 2014.

10. Smylie J, Kirst M, McShane K, et al. Understanding the role of Indigenous community participation in Indigenous prenatal and infant-toddler health promotion programs in Canada: a realist review. Soc Sci Med 2016;150:128-43.

11. Fontaine P. Keynote Panel. Indigenous Health Conference; 2014 Nov. 20; Toronto.

12. Canadian Institutes of Health Research. Natural Sciences and Engineering Research Council of Canada; Social Sciences and Humanities Research Council of Canada. Tri-Council policy statement: ethical conduct for research involving humans. In: Chapter 9: Research involving the First Nations, Inuit, and Métis Peoples of Canada. Ottawa: Secretariat on Responsible Conduct of Research; December 2014:109-137.

13. Tasker JP. Jane Philpott doesn't see 'eye to eye' with Manitoba on First Nations child welfare reforms. CBC News 2018 Jan. 3; updated 2018 Jan. 4. Available: www.cbc.ca/news/politics/jane-philpott-manitoba-child-welfare-1.4460471 (accessed 2019 Feb. 11).

\section{Competing interests: None declared.}

This article was solicited and has not been peer reviewed.

Affiliations: Centre for Urban Health Solutions (Smylie), St. Michael's Hospital; Dalla Lana School of Public Health (Smylie), University of Toronto, Toronto, Ont.; Nanaandawewigamig, First Nations Health and Social Secretariat of Manitoba (Phillips-Beck), Winnipeg, Man.

Contributors: Janet Smylie conceived the article. Both authors drafted the manuscript, revised it critically for important intellectual content, gave final approval of the version to be published and agreed to be accountable for all aspects of the work.

Funding: Janet Smylie is supported by a Canadian Institutes of Health Research, Institute of Population and Public Health, Applied Public Health Research Chair.

Correspondence to: Janet Smylie, janet.smylie@utoronto.ca 